\title{
Prevalence of Overweight among Military Personnel of a Selected Bangladesh Army Unit
} Rahman I', Rustom ATMA ${ }^{2}$, Zafreen $\mathrm{F}^{3}$, Wahab $\mathrm{MA}^{4}$

DOI: https://doi.org/10.3329/jafmc.v14i2.45908

\begin{abstract}
Introduction: Overweight are associated with high rates of morbidity and mortality, but prevalence data on these conditions are not readily available among military personnel in Bangladesh. The aim of this study is to determine the prevalence of overweight and its association with sociodemographic characteristics among military personnel in a unit of Bangladesh Army.
\end{abstract}

Objectives: The aim of the present study was therefore to determine the prevalence of overweight/obesity among military personnel in a military unit of Jalalabad cantonment and also to investigate their association with selected sociodemographic characteristics.

Materials and Methods: A cross-sectional descriptive study was conducted among 385 military personnel. Height weight, BMI were assessed using standardized procedures.

Results: Prevalence of overweight was 54(14\%) and none of the participants were obese or underweight. Overweight status was significantly $(p<0.05)$ higher among $30-45$ years of age group and JCOs. No significant association was found with other socio-demographic characteristics.

Conclusion: Though overall prevalence of overweight was low among military personnel because of their physical hardship and training. But it is significantly higher among the JCOs and younger age groups. Life style modification and education on appropriate diet and physical exercise during formal and informal sessions may be advised.

Key-words: Overweight, Obesity, Military personnel.

\section{Introduction}

The incidence of cardiovascular disease is rapidly increasing at an alarming rate world-wide and is currently considered as the leading cause of death in both developing and developed countries ${ }^{1}$. Report from population-based studies in developing countries, showed an increasing rate of all the cardiovascular risk factors including hypertension, diabetes mellitus, dyslipidemia and obesity2,3. Obesity has been shown to be associated with increased mortality, aggravate common medical conditions such as cardiovascular disease and increase health costs ${ }^{4-8}$. It refers to a medical condition in which excess body fat has accumulated to the extent that it may have an adverse effect on health, leading to reduced life expectancy and/or increased health problems ${ }^{8,9}$. Since obesity has reached epidemic proportions globally, it presence among the military personnel may have adverse consequences on their overall health and efficiency. Also the worsening prevalence of obesity in young civilian adults could hinder the recruitment and maintenance of military man power. Obesity is therefore a major health problem, with an increasing trend of overweight and obese individuals in developing countries. Being overweight or obese is known to contribute significantly to morbidity and mortality rates in various countries around the world ${ }^{4,6,10}$.

Military service is inherently physically demanding therefore all military members must maintain prescribed levels of health and physical fitness. Weight in relation to height is a correlate of health and fitness hence; it is a criterion for recruitment to and continuation in military service in some countries ${ }^{11}$. A report in 2002 , estimated that $13-18 \%$ of men and $17-43 \%$ of women between 17 and 20 years old in the United State exceeded military weight standards ${ }^{11}$. Furthermore, some studies reported a trend toward increasing cardiovascular risk factors among military personnel ${ }^{12-14}$. In Brazil, prevalence of overweight/obesity was estimated at $36 \%$ among young military personne ${ }^{15}$. Another study in Sudan reported prevalence of overweight/obesity as $49.2 \%$, among the police forces ${ }^{16}$. Prevalence of overweight/ obesity has reached epidemic proportions globally with data from the developing countries like Bangladesh scarcely available. Presently, there are few or no empirical data on the prevalence of overweight/obesity among military personnel in Bangladesh.

\section{Materials and Methods}

This cross-sectional descriptive study was conducted among 385 apparently healthy military personnel both gender of 18 to 48 years of age from September to November 2018. All the subjects were selected from BANRDB-2 MONUSCO, C/O $38 \mathrm{E}$ Bengal of Jalalabad cantonment of Bangladesh Army and data were collected in a pre-designed semi-structured questionnaire $a^{t^{51}}$ Field Ambulance of same cantonment. All the participants had no previous history and diagnosis of chronic diseases. Participants' weight were measured by a weighing scale without shoes and with minimal clothing as possible and heights were measured with a stadiometer with barefooted. Height was measured to the nearest $0.1 \mathrm{~cm}$ and weight nearest $0.1 \mathrm{~kg}$. Body mass index (BMI) was calculated by standard formula and was classified based on World Health Organization criteria ${ }^{13}$ as underweight if $<18.5 \mathrm{~kg} / \mathrm{m}^{2}$, normal weight if $18.5-24.9 \mathrm{~kg} / \mathrm{m}^{2}$, overweight if $25-29.9 \mathrm{~kg} / \mathrm{m}^{2}$ and obese if $\geq 30 \mathrm{~kg} / \mathrm{m}^{2}$.

1. Lt Col Irtika Rahman, MBBS, MPH, Commanding Officer, 51 Field Ambulance, Jalalabad Cantonment (E-mail: irtika_71@yahoo.com) 2. Lt Col A T M A Rustom, MBBS, MPH, Senior Medical Officer, BANRDB-2 (MONUSCO).3. Dr Farzana Zafreen, MBBS, MPH, Associate Professor and Head, Department of Community Medicine, Medical College for Women \& Hospital, Uttara, Dhaka. 4. Lt Col Md Abdul Wahab, MBBS, MD, Associate Professor of Biochemistry, AFMC, Dhaka. 
Informed written consent was taken from the participants' before being allowed to participate in the study. Data were analyzed by SPSS 17.0 for Windows and categorical data was expressed as frequency and continuous data as mean $\pm S D$. Chi square test was used to find the association between participants' sociodemographic characteristics and overweight status and $p$-value less than 0.05 considered as significant.

\section{Results}

Out of 385 study subjects $359(93 \%)$ was male and majority $276(71.7 \%)$ were of age group $30-44$ years. Majority of the participants $354(94.5 \%)$ were secondary or more level educated and most of them 348(90.4\%) was married (Table-I). Association of participants' socio-demographic characteristics and overweight status was calculated by Chi square test and found significant $(p<0.05)$ with age group and rank status but nonsignificant with all others (Table-II). Out of 385 participants, $54(14 \%)$ was overweight and the rest was of normal weight and none of them was underweight or obese (Figure-1).

Table-I: Socio-demographic characteristics of the participants

\begin{tabular}{|c|c|c|c|}
\hline \multicolumn{2}{|c|}{ Characteristics } & Frequency & Percentage \\
\hline \multirow{4}{*}{ Age in years } & $18-29$ & 99 & 25.7 \\
\hline & $30-44$ & 276 & 71.7 \\
\hline & $\geq 45$ & 10 & 2.6 \\
\hline & \multicolumn{3}{|c|}{ Range 23-48; Mean \pm SD = 32.46 \pm 5.15} \\
\hline \multirow[b]{2}{*}{ Gender } & Male & 359 & 93.0 \\
\hline & Female & 26 & 7.0 \\
\hline \multirow{2}{*}{ Marital status } & Single & 37 & 9.6 \\
\hline & Married & 348 & 90.4 \\
\hline \multirow{3}{*}{ Education level } & Below secondary & 21 & 5.5 \\
\hline & Secondary & 156 & 40.5 \\
\hline & Above secondary & 208 & 54.0 \\
\hline \multirow{3}{*}{ Rank Status } & Officers & 25 & 6.5 \\
\hline & JCOs & 13 & 3.4 \\
\hline & ORs & 347 & 90.1 \\
\hline
\end{tabular}

Table-II: Association of overweight with different sociodemographic characteristics $(n=385)$

\begin{tabular}{|c|c|c|c|c|}
\hline \multicolumn{2}{|c|}{ Characteristics } & Normal & overweight & Statistics \\
\hline \multirow{3}{*}{ Gender } & Male & $216(60.2)$ & $143(39.8)$ & \multirow{3}{*}{$\begin{array}{l}x^{2}=0.403 \\
d f=1 \\
p>0.05\end{array}$} \\
\hline & Female & $14(53.8)$ & 12(46.2) & \\
\hline & Total & $331(86)$ & $54(14)$ & \\
\hline \multirow{4}{*}{ Age group } & $18-29$ & $92(92.9)$ & $7(7.1)$ & \multirow{4}{*}{$\begin{array}{l}x^{2}=10.112 \\
d f=2 \\
p<0.01\end{array}$} \\
\hline & $30-45$ & $233(84.4)$ & $43(15.6)$ & \\
\hline & $\geq 45$ & $6(60)$ & $4(40)$ & \\
\hline & Total & $331(86)$ & $54(14)$ & \\
\hline \multirow{3}{*}{ Marital Status } & Single & $35(94.6)$ & $2(5.4)$ & \multirow{3}{*}{$\begin{array}{l}\chi^{2}=2.523 \\
d f=1 \\
p>0.05\end{array}$} \\
\hline & \begin{tabular}{|l|} 
Married \\
\end{tabular} & $296(85.1)$ & 52(14.9) & \\
\hline & Total & $331(86)$ & $54(14)$ & \\
\hline \multirow{4}{*}{$\begin{array}{l}\text { Educational } \\
\text { Level }\end{array}$} & Below secondary & $16(76.2)$ & $5(23.8)$ & \multirow{4}{*}{$\begin{array}{l}x^{2}=1.856 \\
d f=2 \\
p>0.05\end{array}$} \\
\hline & Secondary & $136(87.2)$ & $20(12.8)$ & \\
\hline & Above secondary & $179(86.1)$ & $29(13.9)$ & \\
\hline & Total & $331(86)$ & $54(14)$ & \\
\hline \multirow{4}{*}{ Rank status } & Officers & $20(80)$ & $5(20)$ & \multirow{4}{*}{$\begin{array}{l}x^{2}=35.391 \\
d f=2 \\
p<0.001\end{array}$} \\
\hline & $\mathrm{JCOs}$ & $4(30.8)$ & $9(69.2)$ & \\
\hline & ORs & $307(88.5)$ & $40(11.5)$ & \\
\hline & Total & $331(86)$ & $54(14)$ & \\
\hline \multirow{4}{*}{$\begin{array}{l}\text { Regular } \\
\text { physical } \\
\text { exercise }\end{array}$} & No & $9(90)$ & $1(10)$ & \multirow{4}{*}{$\begin{array}{l}x^{2}=0.268 \\
d f=2 \\
p>0.05\end{array}$} \\
\hline & Mild & $285(86.1)$ & $46(13.9)$ & \\
\hline & Moderate to heavy & $37(84.1)$ & $7(15.9)$ & \\
\hline & Total & $331(86)$ & $54(14)$ & \\
\hline \multirow{3}{*}{ Food habit } & Healthy food & $32(76.2)$ & 10(23.8) & \multirow{3}{*}{$\begin{array}{l}x^{2}=3.742 \\
d f=1 \\
p>0.05\end{array}$} \\
\hline & More fatty food & 299(87.2) & $44(12.8)$ & \\
\hline & Total & $331(86)$ & $54(14)$ & \\
\hline
\end{tabular}

- Number in parenthesis is percentage

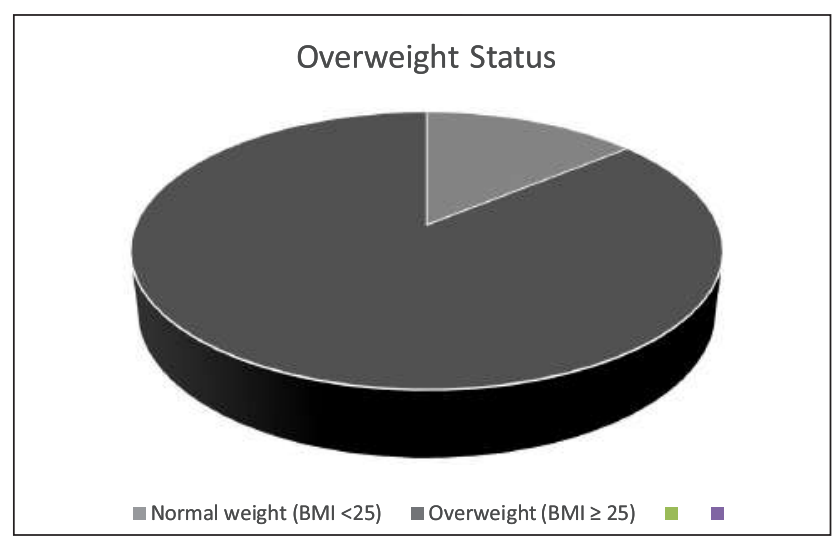

Figure-1: Overweight status according to BMl

\section{Discussion}

The study showed over all prevalence of overweight/obesity was $14.0 \%$ among the military personnel and it is much lower to other military population of different countries. For example prevalence of overweight is $40.4 \%$ among Nigerian military personne ${ }^{17}, 36 \%$ among Brazilian military ${ }^{15}$ and $53 \%$ among USA Navy population ${ }^{18}$. On the other hand, in a systematic review which included only four good-quality community widestudies in Nigeria, Chukwuonyeet $\mathrm{al}^{10}$ found that the prevalence of overweight ranged from $20.3 \%$ to $35.1 \%$, while the prevalence of obesity ranged from $8.1 \%$ to $22.2 \%$ which is nearer prevalence with the present study. Similarly in the Republic of Benin, Ghana and Tanzania prevalence of obesity is as high as $18 \%, 13.6 \%$ and $19.2 \%$ respectively ${ }^{19-21}$ which is almost similar to our study. Systematic reviews of the literature on overweight and obesity carried out in other parts of the world have also showed a high prevalence of overweight/obesity ${ }^{22}$ showing overweight/obesity as one of the leading global epidemic. Another study showed ${ }^{23}$ In the US, the prevalence of obesity has risen from $22.9 \%$ in the late 1980 s and early 1990 s to $30.5 \%$ between 1999 and 2000 . Overweight and obesity are correlates of poor health and physical fitness. The function of the military personnel to defend and protect the citizenry and the nation at large especially in security challenged region can never be over-emphasized.

In presentstudy, the prevalence of overweight found significantly associated with age. This finding is not surprising because evidence indicates that increase in age is a predisposing factor to the development of obesity ${ }^{15,16,24}$. Prevalence of overweight was not significantly associated with marital status in this study but significant association of prevalence of overweight/obesity and being married was reported by smith et al and Desalu et $a^{24,25}$. The higher prevalence and positive associations of overweight/obesity among married military personnel in this study could be attributed to the fact that married personnel tend to be older and perhaps more exposed to a combination of family/home and work stress, are less physically active and may engage in unhealthy eating habits. 
Military personnel from the various countries including Bangladesh can be presumed to be exposed to varying levels of stress, pressures from work, family demands, life style and environmental differences which probably result in variations in the prevalence of overweight/obesity reported across countries. This study has some limitations even though the cross-sectional study design provides reliable and valid information, longitudinal studies should be carried out in other area of Bangladesh also. The study was carried out among a small sample of Bangladeshi military personnel in Sylhet; there is a need to target a larger sample of this occupational group in Bangladesh. Findings from the present study may be difficult to generalize to the general population because the study participants were a unique group. Therefore, results should be used with cautions on other sampled population. Despite the above limitations findings from this study has provided an insight into the prevalence of overweight/ obesity among the young group and its association with different sociodemographic characteristics in some sampled military personnel in Bangladesh. Findings from this study have implication for interventional measures among this occupational group in Bangladesh.

\section{Conclusion}

Overall overweight status of a Bangladesh Army unit is low. But it is significantly higher among the JCOs and younger age groups. Life style modification and education on appropriate diet and physical exercise during formal and informal sessions may be advised. Transformational behavioral changes through military strategies should be addressed. Efforts to maintain healthy weight should be emphasized among military personnel as a practical and high yielding starting point to help keep the overweight under control.

\section{References}

1. Gaziano TA, Bitton A, Anand S, et al. Growing epidemic of coronary heart disease in low- and middle-income countries. Curr Probl Cardiol 2010; 35:72-115.

2. Mellati AA, Mousavinasab SN, Sokhanvar $S$ et al. Correlation of anthropometric indices with common cardiovascular risk factors in an urban adult population of Iran: Data from zanjan healthy heart study. Asian Pacific Journal of Clinical Nutrition 2009; 18:217-25.

3. Sarrafzadegan N, Kelishadi R, Siadat ZD et al. Obesity and cardio metabolic risk factors in a representative population of Iranian adolescents and adults in comparison to a Western population: The isfahan healthy heart programme. Public Health Nutrition 2010; 13:314-23.

4. Allison DB, Fontaine KR, Manson JE, Stevens J, Vanltallie TB. Annual deaths attributable to obesity in the United States. JAMA 1999; 282:1530-8.
5. Seidell JC, Visscher TL, Hoogeveen RT. Overweight and obesity in the mortality rate data: Current evidence and research issues. Med Sci Sports Exerc1999; 31:S597-601.

6. Fontaine KR, Redden DT, Wang C, et al. Years of life lost due to obesity. JAMA 2003; 289:187-93.

7. Dubbert PM, Carithers T, Sumner AE, et al. Obesity, physical inactivity and risk for cardiovascular disease. Am J Med Sci 2002; $324: 116-26$.

8. World Health Organization (WHO) Obesity, preventing and managing the global epidemic; Geneva. ISBN; 2002:92-4.

9. Haslam DW, James WP. Obesity. Lancet 2005; 366:1197-209.

10. Chukwuonye II, Chuku A, John $C$ et al. Prevalence of overweight and obesity in adult Nigerians - A systematic review. Diabetes Metab Syndr Obes 2013; 6:43-7.

11. Nolte R, Franckowiak SC, Crespo CJ, Andersen RE. US military weight standards: What percentage of US young adults meet the current standards? Am J Med 2002; 113:486-90.

12. Ceppa F, Merens A, Burnat P, et al Military community: A privileged site for clinical research: Epidemiological study of metabolic syndrome risk factors in the military environment. Military Medicine 2008; 173:960-7.

13. Flynn D, Johnson JD, Bailey CJet al. Cardiovascular risk factor screening and follow-up in a military population aged 40 years and older. United State Army Medical Department Journal 2009; 67-71.

14. Talbot LA, Weinstein AA, Fleg JL. Army physical fitness test scores predict coronary heart disease risk in army national guard soldiers. Mil Med 2009: 174:245-52.

15. Wenzel D, Souza JM, Souza SB. Prevalence of arterial hypertension in young military personnel and associated factors. Rev Saude Publica 2009; 43:789-95.

16. Aisha AH, Elhassan EAM, Khamis AH, EmaaliAA. (2008) Hypertension and Obesity in police forces households in Khartoum, Sudan. Sudanese Journal of Public Health 3.

17. Adebayo ET, Ogunbiyi OA, Abdulkareem IB, Hussain NA. The Prevalence of obesity in a Nigerian military population. TAF Prev Med Bull 2011; 10:313-8. 
18. Gantt CJ, Neely JA, Villafana IA, et al. Analysis of weight and associated health consequences of the active duty staff at a major Naval medical center. Mil Med 2008; 173:434-40.

19. Sodjinou R, Agueh V, Fayomi B, et al. Obesity and cardiometabolic risk factors in urban adults of Benin: Relationship with socio-economic status, urbanization and lifestyle patterns. BMC Public Health 2008; 8:84.

20. Amoah AG. Obesity in adult residents of Accra, Ghana. Ethn Dis 2003; 13:S97-101.

21. Shayo GA, Mugusi FM. Prevalence of obesity and associated risk factors among adults in Kinondoni municipal district, Dar es Salaam Tanzania. BMC Public Health 2011; 11:365.
22. Berghofer A, Pischon T, Reinhold T et al. Obesity prevalence from a European perspective: A systematic review. BMC Public Health 2008; 8:200.

23. Flegal KM, Carroll MD, Ogden CL, Johnson CL. Prevalence and trends in obesity among US adults, 1999-2000. JAMA 2002; 288: 1723-7.

24. Smith TJ, Marriott BP, Dotson L et al. Overweight and obesity in military personnel: Sociodemographic predictors. Obesity (Silver Spring) 2012; 20:1534-8.

25. Desalu OO, Salami AK, Oluboyo PO, Olarinoye JK. Prevalence and sociodemographic determinants of obesity among adults in an urban Nigerian population. Sahel Medical Journal 2008; 11:61-4. 